\title{
THE IRON BINDING-SITES OF CHICKEN OVOTRANSFERRIN
}

\author{
P.F. LINDLEY ${ }^{+}$, R.W. EVANS*, R.C. GARRATT'* ${ }^{*}$ and S.S. HASNAIN ${ }^{*}$ \\ +Department of Crystallography, Birkbeck College, Malet Street, \\ GB-London WC1E $7 \mathrm{HX}$, Great-Britain \\ *Division of Biochemistry, UMDS, Guy's Hospital st Thomas's \\ street, GB-London SE1 9RT, Great-Britain \\ ** SERC Daresbury Laboratory, GB-Warrington WA4 $4 A D$ \\ Great-Britain
}

\begin{abstract}
We have shown previously that the EXAFS spectrum of diferric chicken ovotransferrin ( $\mathrm{Fe}_{2} \mathrm{COT}$ ) can only be adequately simulated assuming a split first shel1 co-ordination [1]. EXAFS and XANES spectra of $F e_{2} C O T$ measured in solution and as a freeze-dried powder provide evidence for perturbation of the iron-binding sites on freeze-drying which involves the loss of one of the long ( $\sim 2.04 \AA)$ first shell ligands (presumably water). Measurement of the XANES of the C-terminal monoferric COT and a C-terminal domain fragment suggests that the metal binding site remains largely unperturbed by the fragmentation process. The possibility of site interaction is briefly discussed.
\end{abstract}

\section{Introduction}

The role of chicken ovotransferrin (COT) in egg white is presumed to be as a bacteriostatic agent acting via its iron-sequesting capability. Evolutionarily, it is related to serum transferrin, the principal iron transport protein of vertebrate plasma.

The transferrins are monomeric glycoproteins of $\mathrm{Mr} \sim 80,000$ capable of specifically binding a maximum of two ferric ions concomitant with 2 (bi)carbonate anions at homologous iron-binding sites, (for review see [2]). X-Ray diffraction [3] and molecular fragmentation studies have shown the molecule to have a two domain structure. Spectroscopic and chemical modification evidence suggests the presence of histidine and tyrosine ligands to the iron atoms as well as a (bi)carbonate anion and/or water molecule (see [2]). We have shown previously using EXAFS [1] that the the first shell atoms are split into two distances involving 2 light atoms $(\mathrm{O} / \mathrm{N})$ at $\sim 1.85 \mathrm{~A}$ and a further four 1 ight atoms at $\sim 2.04 \mathrm{~A}$.

On the basis of model compounds we assign the shorter distance to the phenolic oxygens of 2 tyrosine residues. A summary of the first shell distances for Fe $\mathrm{COT}_{2}$ and its $\mathrm{N}$ - and $\mathrm{C}$ - domain iron-binding fragments are given in Table 1.

\section{Materials and Methods}

Chicken ovotransferrin and its iron-binding fragments were isolated as described previously [1]. Protein was made iron-saturated by addition of excess Fe(III) nitrilotriacetate and desalted on Sephadex G25. Freeze-dried $\mathrm{Fe}_{2} \mathrm{COT}$ was made by 
shell freezing a solution of iron-saturated protein in $50 \mathrm{mM} \mathrm{NH} \mathrm{NO}_{3}$ using liquid nitrogen and lyophilisation at $\sim 5 \times 10^{-2}$ Torr. C-Monoferric COT was prepared by addition of $0.03 \mathrm{vol}$ of $0.6 \mathrm{M}$ sodium citrate, $\mathrm{pH} 5.0$, to a solution $(20 \mathrm{mg} / \mathrm{ml})$ of $\mathrm{Fe}_{2} \mathrm{COT}$ in water. After the extinction at $470 \mathrm{~nm}$ had fallen to $30 \%$ of its original value a theoretical threefold excess of desferrioxamine was added and the resulting iron-desferrioxamine complex removed by gel filtration on $G-50$. The monoferric protein was freeze-dried prior to use. All solution EXAFS and XANES were recorded in $0.1 \mathrm{M} \mathrm{NaHCO}{ }_{3}$.

$\mathrm{X}$-Ray absorption spectra were recorded on Station 8.1 of the SERC Daresbury SRS, using a double focusing Si (220) monochromator. During data collection the SRS beam energy was $2 \mathrm{GeV}$ and maintained an average circulating current of $220 \mathrm{~mA}$. Simulation of the EXAFS region have involved an approach described elsewhere [4].

Table 1 First shell EXAFS parameters used in the simulation of spectra from $\mathrm{Fe} 2$ COT and its $\mathrm{N}$ - and $\mathrm{C}$ - terminal single domain fragments.

\begin{tabular}{lccccccc}
\hline & & \multicolumn{2}{c}{$\mathrm{N}$ - Fragment } & \multicolumn{2}{c}{ C- Fragment } & \multicolumn{2}{c}{$\mathrm{Fe}_{2} \mathrm{COT}$} \\
\hline Atom & No & $\mathrm{R}(\AA)$ & $\sigma\left(\AA^{2}\right)$ & $\mathrm{R}(\AA)$ & $\sigma\left(\AA^{2}\right)$ & $\mathrm{R}(\AA)$ & $\sigma\left(\AA^{2}\right)$ \\
\hline 0 & 2 & 1.83 & 0.005 & 1.87 & 0.005 & 1.85 & 0.006 \\
$\mathrm{~N}$ & 4 & 2.04 & 0.002 & 2.06 & 0.005 & 2.04 & 0.003 \\
\hline
\end{tabular}

\section{Results and Discussion}

Fig 1 shows a comparison of the EXAFS of $\mathrm{Fe}_{2} \mathrm{COT}$ recorded in $0.1 \mathrm{M} \mathrm{NaHCO}_{3}$ buffer and as a freeze-dried powder. The amplitude and frequency of the major shell contribution is reduced in the freeze-dried sample suggesting the loss of a ligand from the first co-ordination sphere. This is evident in the Fourier transform (inset) where the first shell is shifted to lower $R$ and is of reduced intensity. Rearrangement of some of the outer shells is also apparent from the $3 \AA$. region of the Fourier transform.

The enhancement of features a and b (Fig 2) in the edge structure of the freeze-dried protein confirm that geometrical changes have occurred as a consequence of freeze-drying. Some evidence [5] has been provided for a negative correlation between the intensity of the pre-edge feature a and the co-ordination number. The increased intensity of this transition in the freeze-dried spectrum is therefore consistent with the loss of a ligand from the metal binding-sites.

Fig $3 a$ shows the experimental spectrum for the freeze-dried protein superimposed upon the theoretical simulation for the solution sample [1]. Removal of one ligand from the $2.04 \AA$ shell (Fig 3b) without refinement produces an improvement in the fit index from 0.5 to 0.3 . Refinement of this model reduces the fit index to 0.16 (Fig 3c). We suggest the most probable explanation for these effects is that a co-ordinated water molecule is lost on freeze-drying which results in minor ligand rearrangement including the shortening of the 'long' first shell distance to $2.02 \AA$. E.p.r. measurements at $77 \mathrm{~K}$ (not presented here) confirm the observed perturbation at the iron sites as a consequence of freeze-drying.

The near edge structure for $\mathrm{Fe}_{2} \mathrm{COT}$, the $\mathrm{N}$ - and $\mathrm{C}$ - terminal single domain fragments and the $\mathrm{C}$ - monoferric intact molecule (in which the $\mathrm{N}$ - site is unoccupied) are shown in Fig 4. The similarity of the $\mathrm{C}$ - terminal fragment and its monoferric counterpart suggests that the iron site remains largely unperturbed by the fragmentation process. 


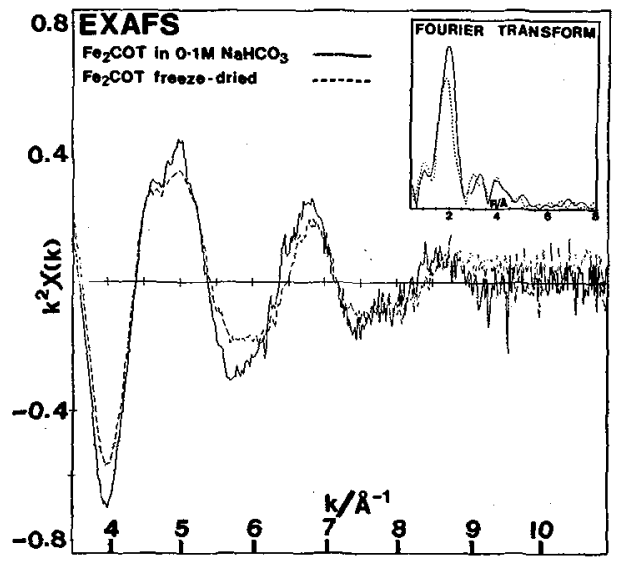

Figure 1 EXAFS and Fourier transforms Tinset) of $\mathrm{Fe}_{2} \mathrm{COT}$ recorded in $0.1 \mathrm{M} \mathrm{NaHCO}_{3}$ $(-\infty)$ and as a freeze-dried powder $(--)$.

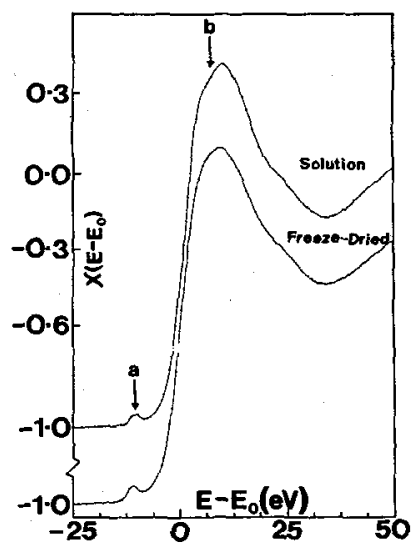

Figure 2 XANES spectra of $\mathrm{Fe}_{2} \mathrm{COT}$ in $0.01 \mathrm{M} \mathrm{NaHCO}$ solution (above) and as a freeze-dried powder (below).

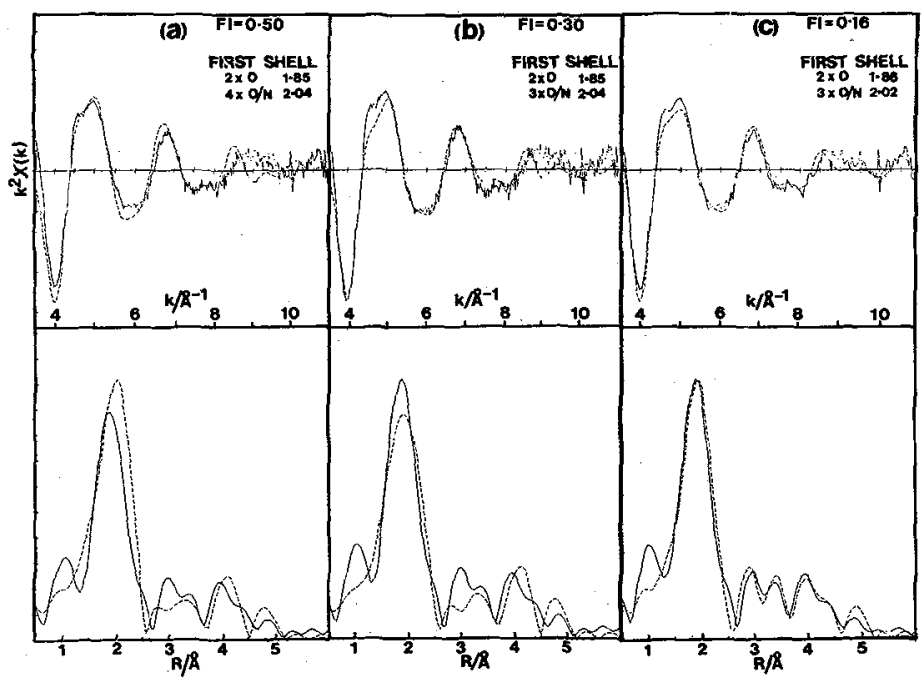

Figure 3 Simulation of the freeze-dried $\mathrm{Fe}_{2} \mathrm{COT}$ EXAFS experiment (-), theory (--). FI is the fit index (a) parameters are those for $F \theta_{2}$ COT in solution [1]. (b) assuming a $2 / 3$ split first shell, (c) as in (b) after refinement.

The similarity of all spectra shown in Fig 4 means that it is not possible to definitely determine any structural interaction between the sites of chicken ovotransferrin, despite the fact that interdomain interactions are known to occur [6] and that the protein shows cooperativity for iron binding [7]. However, recently collected data on human serum transferrin which is reported elsewhere [8] has demonstrated that for the human protein at least, such intersite communication does result in significant geometrical changes at the iron sites which are observed in the edge structure. 


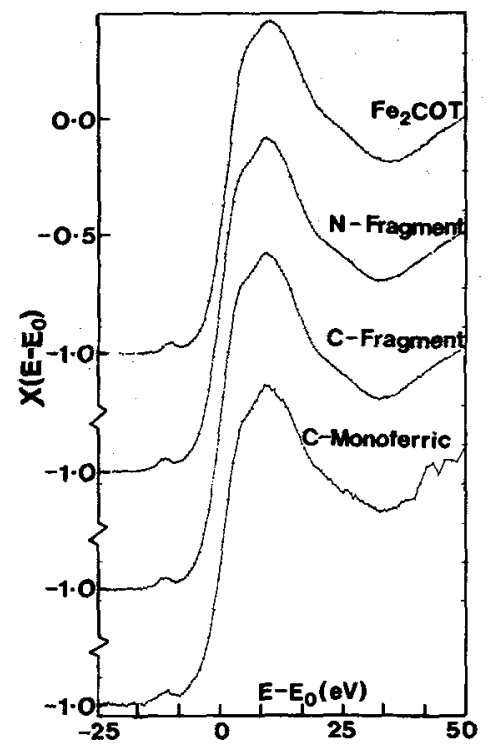

Figure 4 XANES spectra of $\mathrm{Fe}, \mathrm{COT}$, the $\mathrm{N}$ - and $\mathrm{C}$ - terminal single domain fragments and the $\mathrm{C}$ - monoferric intact molecule.

\section{Acknowledgements}

We gratefully acknowledge the SERC for financial support and provision of facilities.

\section{References}

[1] Garratt R C, Evans R W, Hasnain S S \& Lindley P F (1986) Biochem J, 233, 479 $-484$.

[2] Brock J (1985) in Metalloproteins part 2: metal proteins with non-redox roles' (Harrison P, ed) MacMillan Press, Basingstoke, pp 183 - 262.

[3] Gorinsky B, Horsbaugh C, Lindley P F, Moss D, Parkar M \& Watson J L (1979) Nature (London) $281,157-158$.

[4] Blackburn N J, Hasnain S S, Binstead N, Diakun G P, Garner C D \& Knowles P F (1984) Biochem J. 219, 985 - 990.

[5] Roe A L, Schneider D J, Mayer R J, Pyrz J W, Widom J \& Que L, Jr. (1984) J Am Chem Soc 106, 1676 - 1681.

[6] Evans $R$ W, Madden A D \& Patel $K$ J (1985) Biochem Soc Trans. 13,348 - 349.

[7] Yamamura T, Ikeda H, Nakazato K, Takimura M \& Satake $K$ ' (1985) in 'Proteins of iron storage and transport' (Spik G, Montreuil J, Crichton R R \& Mazurier J, eds) Elsevier, Amsterdam, pp 53 - 56.

[8] Garratt R C, Evans R W, Hasnain S S \& Lindley P F (1986) in Proceedings of conference on Biophysics and Synchrotron Radiation, Frascati. 